\title{
The therapeutic potential of duloxetine in prostate cancer-related fatigue
}

\author{
Rita De Sanctis ${ }^{1}$, Alessandro Viganò ${ }^{2,3}$ \\ ${ }^{1}$ Department of Medical Oncology and Haematology, Humanitas Clinical and Research Center, IRCCS, 20089 Rozzano, Italy. \\ ${ }^{2}$ Department of Neurology and Psychiatry, Sapienza University, 00185 Rome, Italy. \\ ${ }^{3}$ Department of Anatomy, Histology, Forensic Medicine and Orthopaedics, Sapienza University, 00185 Rome, Italy.
}

Correspondence to: Dr. Rita De Sanctis, Department of Medical Oncology and Haematology, Humanitas Clinical and Research Center, IRCCS, 20089 Rozzano, Italy. E-mail: rita.de_sanctis@cancercenter.humanitas.it

\section{A B S T R A C T}

Cancer-related fatigue (CRF) is a common polysymptomatic syndrome with no standard therapy. The authors present the case of a prostate cancer patient in whom, during hormone therapy, disabling CRF and urinary incontinence occurred. CRF was assessed according to the brief fatigue inventory (BFI). The patient received duloxetine, $60 \mathrm{mg}$ daily, due to its impact on both CRF and incontinence. After 2 months, the BFI score decreased (from 9 to 2 ) and urinary incontinence resolved. After duloxetine discontinuation, the patient maintained a low BFI score. The authors conclude that, as a serotonin-noradrenaline reuptake inhibitor, duloxetine could be active on prostate CRF, especially with associated urinary symptoms. Therefore, a pilot placebo-controlled trial with duloxetine to treat prostate CRF may be worthwhile.

Key words: Duloxetine; fatigue; prostate cancer

\section{INTRODUCTION}

According to National Comprehensive Cancer Network guidelines, cancer-related fatigue (CRF) is a distressing, persistent, subjective sense of physical, emotional and cognitive tiredness due to cancer and/or its treatments, which is not proportional to real daily living activity. ${ }^{[1]}$ Diagnosis of CRF depends on the administration of multidimensional scales, albeit to date the superiority of one scale compared to the others is not yet well defined. ${ }^{[2]}$

Generally, $60-90 \%$ of all cancer patients under specific treatment and $30-75 \%$ of cancer survivors present CRF. ${ }^{[3]}$ It has been reported that about $74 \%$ of prostate cancer patients experience fatigue. ${ }^{[4]}$ This association is due, in part, to the impact that androgen deprivation, the mainstay of pharmacological prostate cancer treatment, has on the pathophysiological mechanism of CRF. ${ }^{[5]}$

Most prostate cancer patients receive hormone therapy (HT) during their lifetime since it is used for localized disease, as neoadjuvant/adjuvant to radiotherapy or surgery, or for biochemical relapse following radical local treatment. Furthermore, HT often constitutes the sole

\begin{tabular}{|l|l|}
\hline \multicolumn{3}{|c|}{ Access this article online } \\
\hline Quick Response Code: & Website: \\
\hline & www.jcmtjournal.com \\
\cline { 2 - 2 } & \\
\hline
\end{tabular}

treatment for localized disease in patients unsuitable for curative therapy or for metastatic disease. At early stages, $17 \%$ of patients undergoing HT complain about severe fatigue. ${ }^{[6]}$ In patients receiving both radiotherapy and HT, the prevalence of chronic fatigue is about $39 \%{ }^{[7]}$

CRF is a complex, polysymptomatic syndrome caused by direct and/or indirect effects of neoplastic lesions, supportive care management, comorbidities and related medications, and environmental and psycho-emotional aspects. Although CRF patho-physiology is still not completely understood, each of these above mentioned factors can cooperate to lead to an abnormal production and use of adenosine triphosphate, an increase in proinflammatory cytokines, adhesion molecule and acute phase proteins. These metabolic changes are responsible for sleep-wake rhythm disorders and alterations of central nervous system mediators (corticotropin-releasing hormone increase, serotonin release and dopamine decrease). ${ }^{\left[{ }^{8]}\right.}$

In one study, only $9 \%$ of patients with CRF were treated, and the rate of success was quite low. ${ }^{[9]}$ At present, no satisfactory standard therapy for CRF is available. ${ }^{[10]}$

This is an open access article distributed under the terms of the Creative Commons Attribution-NonCommercial-ShareAlike 3.0 License, which allows others to remix, tweak, and build upon the work non-commercially, as long as the author is credited and the new creations are licensed under the identical terms.

For reprints contact: service@oaepublish.com

How to cite this article: De Sanctis R, Viganò A. The therapeutic potential of duloxetine in prostate cancer-related fatigue. J Cancer Metastasis Treat 2016;2:64-6.

Received: 21-01-2015; Accepted: 30-07-2015 
Corticosteroids can be useful but are not devoid of major side effects. Some evidence supports the use of methylphenidate over placebo, but its use is limited by side effects, and it should be administrated only under expert supervision. One placebo-controlled trial on methylphenidate in prostate cancer showed a small benefit. However, $37.5 \%$ of treated subjects dropped out for severe drug-related adverse events. Secondly, the sample size was quite small, and statistical analysis was not corrected for multiple comparisons. ${ }^{[11]}$

Also, erythropoietin may be effective but a specific dose for routine practice in CRF cannot be recommended. The aim of treatment should be to use the minimum required dose for the shortest duration. ${ }^{[12]}$ This is due to the theoretical increase in the risk of thromboembolic side effects with higher doses and protracted treatment with erythropoietin and possible cancer stimulation. ${ }^{[10]}$

In some trials, antidepressants and psychostimulant drugs showed a small little clinical benefit. ${ }^{[13]}$ Here, we report a case of CRF treated with duloxetine. Duloxetine is a serotoninnoradrenergic reuptake inhibitor, commonly used as an antidepressant. It has been recently approved for neuropathic pain, chronic fatigue syndrome (at the dose range of 30-60 mg daily), fibromyalgia and it is also recommended for urinary incontinence in Europe (40-80 mg daily). ${ }^{[14-16]}$

\section{CASE REPORT}

A 74-year-old man presented to our clinic complaining of more than 6 months of fatigue, which was exacerbated by activity and not relieved by rest. The patient had a history of advanced prostate cancer 3 years before, he underwent a radical prostatectomy (Gleason score $4+4$, pT3bN0; prostate-specific antigen (PSA) $21.1 \mathrm{ng} / \mathrm{mL}$ ) followed by adjuvant radiotherapy. Following treatment, only mild urinary incontinence was noted. Two years later, he had a biochemical relapse, with a PSA doubling time $<6$ months for which he started on daily bicalutamide, $50 \mathrm{mg}$ and monthly luteinizing hormone-releasing hormone agonist. After starting medical therapy, a progressive and significant PSA normalization was observed. However, 6 months later, he complained for recurrent moments of sadness, loss of interest in daily activities, insomnia, concentration problems and worsening urinary incontinence (from mild to moderate).

On physical examination, he was not pale or jaundiced, afebrile with normal heart rate and blood pressure. Heart, lung, abdominal and musculoskeletal examinations were normal. No hepatomegaly, gynecomastia or neurological signs were present. Eastern Cooperative Oncology Group performance status was $0-1$. Laboratory tests, including a complete blood count and electrolytes, showed mild anemia (hemoglobin $11.7 \mathrm{~g} / \mathrm{dL}$ ) and elevated transaminase levels (alanine transaminase $83 \mathrm{U} / \mathrm{L}$, aspartate transaminase
$51 \mathrm{U} / \mathrm{L}$ ) while thyroid, hepatic and renal function were normal. Serological tests for hepatitis B virus, hepatitis $\mathrm{C}$ virus, human immunodeficiency virus, EpsteinBarr virus and cytomegalovirus were negative. Chest radiography, abdominal ultrasound, electrocardiography and echocardiography were all normal.

Diagnosis of CRF was established as a diagnosis of exclusion. CRF was assessed according to the Brief Fatigue Inventory (BFI), ${ }^{[17]}$ and a score of 9 (BFI range, 0-10) was found.

Considering both the urinary incontinence and depression symptoms, we prescribed duloxetine at a starting daily dose of $30 \mathrm{mg}$ and then, as per drug schedule, after 2 weeks, the dose was increased to $60 \mathrm{mg}$. Duloxetine was chosen due to its efficacy against urinary incontinence at a similar dose (dose range, 40-80 mg daily).

After 2 months of treatment at the dose of $60 \mathrm{mg}$, the BFI score was decreased to 2 , urinary incontinence completely resolved, and the patient returned to regular activities. There were no side effects. Duloxetine was continued at the same dose for a further 2 months and then was withdrawn because of alcoholism relapse, a disorder that the patient and his relatives had omitted in medical history. After duloxetine discontinuation, the patient reported a moderate CRF worsening over 6 months. However, 4 months later, he maintained a 5 points-lower BFI score than the initial one. At the same time, he was referred to our alcohol abuse center with a progressive reduction of heavy-drinking days in a 6-month timeline follow-back.

\section{DISCUSSION}

$\mathrm{CRF}$ is a major problem in prostate cancer management, according to several studies, the prevalence of CRF regardless of intensity is about $74 \%{ }^{[4]}$ There is no "gold standard" treatment currently recommended, and the commonly given therapies are poorly successful. Only 2 drugs have shown some activity against CRF: methylphenidate and erythropoietin, although their regular use do have caveats. ${ }^{[10]}$

Our patient, who was not receiving chemotherapy, showed mild anemia, thus not presenting an indication for erythropoietin. Some data show that CRF can disappear spontaneously 6-8 weeks after the end of HT, but our patient was receiving HT, and was to be continued until progression or unacceptable toxicity, so that a medical withdrawal was not indicated. Although the timing and modality of treatment of PSA-only recurrence after radical prostatectomy and radiotherapy remains controversial, our patient had highrisk disease deserving first-line treatment. ${ }^{[18]}$

In CRF pathophysiology, a relevant impairment of neurotransmitter (serotoninergic, noradrenergic and dopaminergic) systems is present. The use of different 
psychoactive drugs increasing neurotransmitter concentrations shows an effect in CRF treatment. The poor outcome of serotonergic drugs, as paroxetine and sertraline, on fatigue in randomized controlled trials could be due to their selective action on the serotonin reuptake. ${ }^{[13,16,19]}$ Nevertheless, it is worth mentioning that a recent study stressed the role of tryptophan (a serotonin precursor) depletion in developing CRF and found a correlation between the higher degree of fatigue and lower tryptophan concentrations. Thus, a drug that acts on more than one mechanism could be appropriate. ${ }^{[13]}$ Modafinil, a non-amphetamine psychostimulant, reduces CRF intensity. ${ }^{[12]}$ Although the precise mechanism of modafinil action has not been elucidated, it seems to rely on the interaction of adrenergic and dopaminergic transmission in prefrontal cortices. ${ }^{[20]}$ Also, methylphenidate could facilitate excitatory synaptic signaling, mainly through strengthening catecholaminergic synaptic transmission. As a blocker of dopamine and norepinephrine transporters, it increases both extracellular dopamine and norepinephrine. ${ }^{[21,22]}$

Considering these data, the use of a drug like duloxetine, that has a pleiotropic action on these pathways, has some rationale in the treatment of CRF. Moreover, in our case, further benefit was derived from its activity on urinary incontinence, thus promoting the patient's sense of wellbeing and, therefore, ameliorating his quality of life and increasing his compliance with physical therapy (mild exercise, daily walking), which has a therapeutic role in $\mathrm{CRF}$ and in social life.

In conclusion, a pilot placebo-controlled trial using duloxetine seems worthwhile since it acts on fatigue, urinary symptoms and depression, all often occurring in a complex and multidimensional disease as prostate cancer CRF.

\section{Financial support and sponsorship}

Nil.

\section{Conflicts of interest}

There are no conflicts of interest.

\section{REFERENCES}

1. National Comprehensive Cancer Network Practice Guidelines. Cancerrelated Fatigue Guidelines; 2014. Available from: http://www.nccn.org. [Last accessed on 2014 Oct 18].

2. Whitehead L. The measurement of fatigue in chronic illness: a systematic review of unidimensional and multidimensional fatigue measures. J Pain Symptom Manage 2009;37:107-28.

3. Meneses-Echávez JF, González-Jiménez E, Ramírez-Vélez R. Effects of supervised multimodal exercise interventions on cancer-related fatigue: systematic review and meta-analysis of randomized controlled trials. Biomed Res Int 2015;2015:328636.
4. Sonn GA, Sadetsky N, Presti JC, Litwin MS. Differing perceptions of quality of life in patients with prostate cancer and their doctors. $J$ Urol 2009;2:2296-302.

5. Saylor PJ, Smith MR. Metabolic complications of androgen deprivation therapy for prostate cancer. J Urol 2009;181:1998-2006.

6. Stone P, Hardy J, Huddart R, A'Hern R, Richards M. Fatigue in patients with prostate cancer receiving hormone therapy. Eur J Cancer 2000;36:1134-41.

7. Kyrdalen AE, Dahl AA, Hernes E, Hem E, Fossa SD. Fatigue in prostate cancer survivors treated with definitive radiotherapy and LHRH analogs. Prostate 2010;70:1480-9.

8. Capuron L, Miller AH. Immune system to brain signalling: neuropsychopharmacological implications. Pharmacol Ther 2011;130:226-38

9. de la Cruz M, Hui D, Parsons HA, Bruera E. Placebo and nocebo effects in randomized double-blind clinical trials of agents for the therapy for fatigue in patients with advanced cancer. Cancer 2010;116:766-74.

10. Minton O, Richardson A, Sharpe M, Hotopf M, Stone P. A systematic review and meta-analysis of the pharmacological treatment of cancerrelated fatigue. J Natl Cancer Inst 2008;20:1155-66.

11. Nelson CJ, Mulhall JP, Roth AJ. The association between erectile dysfunction and depressive symptoms in men treated for prostate cancer. J Sex Med 2011;8:560-6.

12. Carroll JK, Kohli S, Mustian KM, Roscoe JA, Morrow GR. Pharmacologic treatment of cancer-related fatigue. Oncologist 2007;12:43-51.

13. Morrow GR, Hickok JT, Roscoe JA, Raubertas RF, Andrews PL, Flynn PJ, Hynes HE, Banerjee TK, Kirshner JJ, King DK, University of Rochester Cancer Center Community Clinical Oncology Program. Differential effects of paroxetine on fatigue and depression: a randomized, double-blind trial from the University of Rochester Cancer Center Community Clinical Oncology Program. J Clin Oncol 2003;21:4635-41

14. Bellato E, Marini E, Castoldi F, Barbasetti N, Mattei L, Bonasia DE, Blonna D. Fibromyalgia syndrome: etiology, pathogenesis, diagnosis and treatment. Pain Res Treat 2012;2012:426130.

15. Knadler MP, Lobo E, Chappell J, Bergstrom R. Duloxetine: clinical pharmacokinetics and drug interactions. Clin Pharmacokinet 2011;50:281-94

16. Mease PJ. Further strategies for treating fibromyalgia: the role of serotonin and norepinephrine reuptake inhibitors. Am J Med 2009;122:S44-55.

17. Ahlberg K, Ekman T, Gaston-Johansson F, Mock V. Assessment and management of cancer-related fatigue in adults. Lancet 2003;362:640-50.

18. Mottet N, Bastian PJ, Bellmunt J, van den Bergh RC, Bolla M, van Casteren NJ, Cornford P, Joniau S, Mason MD, Matveev V, van der Kwast TH, van der Poel H, Rouvière O, Wiegel T. Guidelines on Prostate Cancer, European Association of Urology; 2014. Available from: http:// www.uroweb.org/wp-content/ uploads/1607-Prostate-Cancer_LRV3.pdf. [Last accessed on 2015 Aug 14].

19. Roscoe JA, Morrow GR, Hickok JT, Mustian KM, Griggs JJ, Matteson SE, Bushunow P, Qazi R, Smith B. Effect of paroxetine hydrochloride (Paxil) on fatigue and depression in breast cancer patients receiving chemotherapy. Breast Cancer Res Treat 2005;89:243-9.

20. de Saint Hilaire Z, Orosco M, Rouch C, Blanc G, Nicolaidis S. Variations in extracellular monoamines in the prefrontal cortex and medial hypothalamus after modafinil administration: a microdialysis study in rats. Neuroreport 2001;12:3533-7.

21. Kuczenski R, Segal DS. Effects of methylphenidate on extracellular dopamine, serotonin, and norepinephrine: comparison with amphetamine. J Neurochem 1997;68:2032-7.

22. Gronier B. In vivo electrophysiological effects of methylphenidate in the prefrontal cortex: involvement of dopamine D1 and alpha 2 adrenergic receptors. Eur Neuropsychopharmacol 2011;21:192-204. 